\title{
ANALISA PENILAIAN KELAYAKAN JAMINAN DALAM PENGAMBILAN KEPUTUSAN KREDIT UMKM PADA LEMBAGA KEUANGAN DI INDONESIA
}

\author{
Aris Kurniawan \\ Dosen Program Studi Administrasi Bisnis, Universitas Bina Sarana Informatika (UBSI) \\ Jl. Kamal Raya No. 18, Ringroad Barat, Cengkareng, Jakarta Barat \\ Email: aris.aku@bsi.ac.id
}

\begin{abstract}
The research tries to explain credit guarantees that are generally accepted by banks, especially in the MSME credit segment. The author tries to explain best practices related to credit guarantees, credit guarantee assessment and, types of guarantees that are generally avoided by banks. The object in this study is a bank that serves financing or credit, especially the UMKM segment, both government banks and private banks. The research method used was descriptive qualitative. Sources of data used are data that the authors obtained from the bank's official website which is the object of research. In addition, the author also collects brochures from several banks, other supporting data is the credit policy guidebook that the author has where the author has worked at several of these banks. To complete the information and data, the author also conducted interviews with several marketing banks. The results of the discussion in this study explain the types of collateral generally accepted by banks are land and buildings, vacant land, kiosks, motorized vehicles 2 and 4 and deposits. For LTV (Loan To Value) or the ratio of the amount of the loan compared to the guarantee provided, among others, a maximum of 70-80\% vacant land, $80 \%$ maximum land and buildings, 60-70\% maximum motorized vehicles and a maximum deposit of 90\%. The guarantees generally avoided by banks for land and buildings are guarantees intended for green lines, road widths less than one meter, under high voltage electricity, carried by heavy currents, land in dispute, land and buildings designated and used for public and religious facilities etc .
\end{abstract}

Keywords:.Credit, Guarantee, Loan To Value.

\begin{abstract}
ABSTRAK
Peneliti mencoba menjelaskan tentang jaminan kredit yang umumnya diterima perbankan khususnya pada segment kredit UMKM, penulis berusaha menjelaskan secara best practice terkait jaminan kredit, penilaian jaminan kredit dan jenis jaminan yang umumnya dihindari oleh perbankan. Objek dalam penelitian ini adalah bank yang melayani pembiayaan atau kredit khususnya segment UMKM baik bank pemerintah maupun bank swasta. Metode penelitian yang digunakan deskriptif kualitatif. Sumber data yang yang digunakan adalah data-data yang penulis peroleh dari web resmi bank yang dijadikan objek penelitian. Disamping itu penulis juga mengumpulkan brosur beberapa bank, data pendukung lainya adalah buku pedoman kebijakan kredit yang penulis miliki dimana penulis pernah bekerja pada beberapa bank tersebut. Untuk melengkapi informasi dan data penulis juga melakukan wawancara dengan beberapa marketing bank. Hasil Pembahasan dalam penelitian ini menjelaskan jenis jaminan yang umumnya diterima perbankan adalah tanah dan bangunan, tanah kosong, kios, kendaraan bermotor roda 2 dan 4 serta deposito. Untuk LTV (Loan To Value) atau rasio besarnya pinjaman dibandingkan dengan jaminan yang diberikan antara lain tanah kosong maksimal 70-80\%, tanah dan bangunan maksimal 80\%, kendaraan bermotor maksimal 60-70\% dan deposito maksimal $90 \%$. Adapun jaminan yang umumnya dihindari oleh perbankan untuk tanah dan bangunan adalah, jaminan yang diperuntukan untuk jalur hijau, lebar jalan kurang dari satu meter, dibawah aliran listrik bertegangan tinggi, dibantaran kali arus deras, tanah dalam sengketa, tanah dan bangunan yang peruntukan dan dipakai untuk fasilitas umum dan kegamaan dan lainlain.
\end{abstract}

Kata kunci: Kredit, Jaminan, Loan To Value. 


\section{PENDAHULUAN}

\subsection{Latar belakang}

Dunia perbankan memiliki peranan penting dalam perekonomian suatu negara. Indonesia sebagai negara berkembang kemajuan ekonominya salah satunya bersumber dari kontribusi dunia perbankan. Perkembangan ekonomi Indonesia diikuti pula dengan peningkatan jumlah usaha besar, usaha menengah, kecil dan mikro (UMKM). Usaha Mikro, Kecil dan Menengah (UMKM) memiliki peran yang penting dan strategis dalam pembangunan ekonomi nasional karena mampu menciptakan lapangan kerja dan mendorong pertumbuhan ekonomi. Sektor UMKM juga telah terbukti tidak terpengaruh terhadap krisis ekonomi, saat krisis ekonomi terjadi pada periode tahun 1997-1998, UMKM merupakan usaha yang tetap mampu berdiri kokoh, data Badan Pusat Statistik memperlihatkan, pasca krisis ekonomi tahun 1997-1998 jumlah pelaku UMKM di Indonesia tidak berkurang, bahkan terjadi peningkatan, serta mampu menyerap 85 juta hingga 107 juta tenaga kerja sampai tahun 2012.

Salah satu kegiatan utama perbankan adalah menyalurkan kredit kepada masayarakat khususnya pelaku usaha, Kredit mempunyai peranan penting dalam perekonomian karena membantu seseorang atau pelaku usaha yang mengalami kesulitan keuangan untuk mengembangkan usahanya. Dengan pemberian kredit diharapkan dapat memajukan kegiatan perekonomian serta meningkatkan taraf hidup masyarakat. Kredit juga memiliki fungsi dalam perekonomian sebagai sarana untuk meningkatan daya guna barang dan uang, lalu lintas pembayaran, dan mendorong gairah berwirausaha, dan sebagai alat stabilitas moneter.

Tujuan pemberian kredit pada umumnya adalah mencari keuntungan berbentuk imbalan atau bagi hasil, kredit merupakan pendapatan utama perbankan dalam meningkatkan laba. Perbankan memiliki banyak jenis kredit salah satunya adalah kredit mikro. Kredit mikro bukanlah konsep baru di bidang ekonomi. Konsep ini dipelopori dari Grameen Bank, yang dirintis oleh Professor Muhammad Yunus di tahun 70'an, dengan memberikan pinjaman kecil kepada pelaku UMKM tanpa jaminan. Tidaklah mengherankan bila mayoritas peminjamnya pada saat itu adalah wanita (sekitar 95\%), yang umumnya tidak memiliki pemasukan tetap yang memadai serta menghadapi banyak keterbatasan untuk mengajukan pinjaman melalui jalur bank atau institusi finansial konvensional.

Kredit UMKM saaat ini merupakan salah satu segmen kredit yang banyak diminati oleh perbankan di Indonesia sebagai target market, tingginya margin dan potensi keuntungan yang dijanjikan dari penyaluran kredit UMKM merupakan salah satu alasannya, Namun dalam fakta penyalurannya segmen kredit ini merupakan salah satu yang dianggap memiliki potensi risiko yang cukup tinggi. salah satu alasanya adalah pelaku UMKM belum memiliki manajemen usaha yang baik, menjalankan usaha dengan kebiasaan atau turun temurun, usaha yang mudah berpindah atau bertukar jenis usaha dan banyak faktor lainnya.

Dalam penyaluran kredit, tentunya bank tidak terlepas dari adanya potensi risiko yang akan di hadapi, semakin besar pembiayaan atau kredit yang disalurkan maka akan semakin besar pula potensi risiko yang akan dihadapi. Adapun risiko yang akan dihadapi oleh bank berupa tidak lancarnya kredit atau dengan kata lain kredit bermasalah yang dapat mengganggu kinerja bank. Untuk itu diperlukan suatu metode analisa kredit sebelum pembiayaan atau kredit dikucurkan kepada calon debitur. Prinsip analisa kelayakan kredit yang biasa dipakai perbankan adalah dengan metode 5C (Character, Capacity, Collateral, Capital dan Condition), kelima unsur ini sangat penting diterapkan secara 
komprehensip dalam mengambil keputusan pemberian kredit.

Salah satu unsur utama dalam metode analisa kredit yang akan dibahas khusus dalam penelitian ini adalah tentang jaminan (Collateral). Agunan atau jaminan merupakan pengaman atau sering disebut dengan second way out bagi bank jika dihadapkan dengan masalah kredit macet, dengan kata lain agunan merupakan salah satu alternatife terakhir untuk menjadi sumber pembayaran kredit yang telah disalurkan.

Untuk itu dalam melakukan analisis dan menilai kelayakan agunan atau jaminan yang diberikan calon debitur diperlukan suatu acuan dan teknik untuk menilai apakah jaminan atau agunan tersebut layak dan dapat mengcover jumlah kredit yang akan diberikan. Umumnya jenis jaminan yang biasa diterima perbankan adalah tanah dan bangunan, tanah kosong, kendaraan bermotor dan Deposito.

Penelitian sebelumnya skripsi Nazar dengan judul Analisis Penilaian Agunan Dalam Keputusan Pemberian Pembiayaan Murabahah Pada BMT Mitra Dana Sakti Lampung Selatan dalam penelitian ini kesimpulan utamanya adalah bank menilai jaminan calon debitur sebesar $80 \%$ dari nilai market.

Berdasarkan uraian pada latar belakang masalah di atas dalam penilitian ini penulis akan memfokuskan pembahasan pada penilaian jaminan kredit atau pembiayaan yang secara best practice umum nya diterapkan oleh perbankan khusus nya dalam segmen kredit UMKM.

\subsection{Rumusan Masalah}

Berdasarkan latar belakang yang telah diuraikan, maka penulis mengidentifikasikan masalah pada penelitian ini sebagai berikut:

1. Jenis jaminan apa saja yang diterima perbankan dalam pemberian Kredit UMKM?

2. Berapa besarnya LTV (loan to value) untuk masing-masing jenis jaminan?

3. Kondisi dan jenis jaminan apa saja yang umumnya dihindari oleh perbankan?

\subsection{Tujuan Penelitian}

1. Untuk mengetahui dan menganalisis jenis jaminan apa saja yang diterima perbankan dalam pemberian Kredit UMKM?

2. Untuk mengetahui mengetahui dan menganalisis berapa besarnya LTV (loan to value) untuk masing-masing jenis jaminan?

3. Untuk mengetahui mengetahui dan menganalisis kondisi dan jenis jaminan apa saja yang umumnya dihindari oleh perbankan?

\section{TINJAUAN PUSTAKA}

\subsection{Landasan Teori}

\subsubsection{Pengertian Kredit}

Kredit berasal dari bahasa Yunani, yaitu "credere", yang berarti kepercayaan (Wahjono, 2013).

Menurut UU. No.10 Tahun 1998 tentang perbankan, disebutkan bahwa kredit adalah suatu penyediaan uang atau tagihan yang dapat disamakan dengan itu, berdasarkan persetujuan atau kesepakatan pinjam-meminjam antara bank dan pihak lain yang mewajibkan pihak peminjam untuk melunasi utangnya setelah jangka waktu tertentu dengan pemberian bunga (Undang-undang RI No. 10, 1998). Dari uraian ini dapat kita simpulkan bahwa kredit diberikan kepada seseorang atau lembaga dengan pertimbangan kepercayaan, risiko, waktu, dan prestasi. Kepercayaan berarti kredit yang diberikan akan dikembalikan dalam jangka waktu yang telah disepakati beserta imbalan (prestasi) dari pemberi kredit tersebut.

\subsubsection{Fungsi Kredit}

Kredit juga memiliki fungsi yaitu sebagai berikut (Kasmir, 2012): 
a. Untuk meningkatkan daya guna uang dengan adanya kegiatan kredit, uang tersebut menjadi berguna untuk mengasilkan barang atau jasa yang di peroleh debitur yang akan menghasilkan bunga untuk pemberi kredit.

b. Untuk meningkatkan daya guna barang kredit yang diberikan oleh bank akan dapat digunakan oleh debitur untuk mengolah barang yang tidak berguna menjadii berguna atau bermanfaat.

c. Meningkatkan peredaran barang kredit dapat pula menambah atau memperlancar arus barang dari satu wilayah ke wilayah lainnya, sehingga barang yang beredar dari satu wilayah ke wilayah lainnya bertambah. Meningkatkan peredaran dan lalu lintas uang Uang yang diberikan atau disalurkan akan beredar dari satu wilayah ke wilayah lainnya sehingga, suatu daerah yang kekurangan uang dengan memperoleh tambahan uang dari daerah lainnya.

\subsubsection{Prinsip Pemberian Kredit}

Persetujuan pemberian kredit oleh bank kepada nasabah selalu mempertimbangkan prinsip 5C yang terdiri dari (Kasmir, 2012):

a. Character

Lebih menekankan pada ukuran kemauan nasabah dalam memenuhi kewajibannya. Hal-hal yang berhubungan dengan prinsip Character ini dapat dilihat dengan meneliti riwayat hidup nasabah, reputasi calon debitur tersebut di lingkungan usaha, dan meminta informasi antar bank.

\section{b. Capital}

Sama-sama digunakan untuk melihat penggunaan modal apakah efektif, dilihat laporan keuangan (neraca dan laporan laba rugi) dengan melakukan pengukuran yang ditunjukkan melalui analisis angka rasio, seperti segi likuiditas, solvabilitas, rentabilitas, dan ukuran lainnya serta juga harus dilihat dari sumber mana saja modal yang ada sekarang ini.

c. Capacity

Prinsip Capacity sama-sama melihat kemampuan debitur dalam menjalankan bisnis dalam bidang usahanya sehingga akan terlihat juga kemampuannya dalam mengembalikan kredit yang disalurkan. Hal-hal yang harus diperhatikan oleh bank antara lain melihat angka-angka hasil produksi, angka-angka penjualan dan pembelian, perhitungan laba-rugi perusahaan saat ini dan proyeksinya, serta data-data keuangan diwaktu lalu yang terdapat pada laporan keuangan guna mengukur kemampuan calon debitur untuk melaksanakan rencana kerjanya di waktu yang akan datang.

d. Collateral

Prinsip Collateral merupakan jaminan yang diberikan calon nasabah baik yang bersifat fisik maupun non fisik. Jaminan hendaknya melebihi jumlah kredit yang diberikan. Jaminan juga harus diteliti keabsahannya sehinggga jika terjadi suatu masalah, maka jaminan yang dititipkan akan dapat dipergunakan secepat mungkin.

e. Condition

Condition dalam hal ini menilai kredit dari kondisi ekonomi dan politik sekarang dan dimasa yang akan datang sesuai sektor masingmasing, serta prospek usaha dari sektor yang dijalankan.

\subsubsection{Pengertian Jaminan}

Agunan dalam terminologi hukum perbankan didefinisikan dalam Pasal 1 angka 23 UU No. 10 Tahun 1998 tentang Perbankan sebagai suatu jaminan tambahan yang diserahkan nasabah (debitur) kepada bank (kreditur) dalam rangka pemberian 
fasilitas kredit atau pembiayaan berdasarkan prinsip syariah. (Undangundang RI No. 10, 1998).

Menurut Otoritas Jasa Keuangan Agunan adalah jaminan tambahan yang diserahkan nasabah debitur kepada bank dalam rangka pemberian fasilitas kredit atau pembiayaan berdasarkan prinsip syariah (collateral). (OJK-PEDIA, 2020).

\subsubsection{Jenis Jaminan}

Menurut Peraturan Bank Indonesia (BI) No. 9/PBI/2007, bentuk Jaminan yang diakui untuk suatu pinjaman antara lain adalah (Banu Rinaldi, 2020) :

a. Tanah, di mana kepemilikan tanah harus dibuktikan lewat hak milik, hak guna usaha, hak pakai atas tanah Negara, dan lain-lain.

b. Bangunan, termasuk di antaranya adalah

c. rumah tinggal, rumah susun, pabrik, gudang, hotel, dan lainnya. Jaminan jenis ini harus dilengkapi dengan IMB (Izin Mendirikan Bangunan).

d. Kendaraan Bermotor, termasuk di antaranya adalah mobil dengan berbagai jenis, merek, dan tipe serta sepeda motor dan skuter. Kepemilikannya harus dibuktikan dengan Bukti Pemilikan Kendaraan Bermotor (BPKB).

e. Mesin Pabrik, di mana usia mesin dan kemampuan teknisnya akan dianalisa terlebih dulu untuk menentukan nilainya.

f. Surat Berharga dan Saham, yang harus berstatus aktif dalam perdagangan di Bursa Efek Indonesia (BEI) atau memiliki peringkat investasi.

g. Pesawat Udara atau Kapal Laut, dengan syarat memiliki ukuran di atas 20 meter kubik yang sudah diikat dengan hipotek.

h. Emas : Aset ini bisa dijadikan Jaminan dalam pinjaman karena memenuhi kriteria, namun tidak bisa diterima di bank konvensional lantaran tidak diizinkan oleh Bank Indonesia.

Solusinya adalah dengan mengagunkan emas ke lembaga pembiayaan lainnya, seperti Bank Syariah.

i. Deposito : Sejumlah bank bersedia menerima deposito sebagai pinjaman.

j. Piutang Usaha : Dapat digunakan sebagai Jaminan untuk Pinjaman Jangka Pendek. Jenis Pinjaman dengan Jaminan ini disediakan oleh Bank dengan jangka waktu pembayaran yang tidak lebih dari beberapa minggu.

\subsubsection{Fungsi Jaminan}

Fungsi jaminan kredit dapat ditinjau dari sisi bank maupun sisi debitur dapat di uraikan sebagai berikut: (Bahsan, 2007)

a. Jaminan Kredit sebagai Pengamanan Pelunasan Kredit

Bank sebagai badan usaha yang memberikan kredit kepada debitur wajib melakukan upaya pengamanan agar kredit tersebut dapat dilunasi debitur yang bersangkutan. Sekecil apapun nilai uang dari kredit yang telah diberikan pada debitur tetap harus diamankan sesuai dengan prinsip kehati-hatian. Keterkaitan jaminan kredit dengan pengamanan kredit dapat disimpulkan dari ketentuan Pasal 1131 KUH Perdata sehingga merupakan upaya alternatif yang dapat digunakan bank untuk memperoleh pelunasan kredit pada waktu debitur ingkar janji kepada bank.Bila dikemudian hari debitur ingkar janji, yaitu tidak melunasi utangnya kepada bank sesuai dengan ketentuan perjanjian kredit, akan dilakukan pencairan / penjualan atas objek jaminan kredit yang bersangkutan. Hasil pencairan jaminan kredit tersebut selanjutnya diperhitungkan oleh bank untuk pelunasan kredit debitur yang telah dinyatakan sebagai kredit macet.

b. Jaminan Kredit sebagai Pendorong Motivasi Debitur 
Umumnya, sesuai dengan ketentuan masing-masing bank, nilai jaminan kredit yang diserahkan debitur kepada bank lebih besar dibandingkan nilai kredit yang diberikan bank pada debitur yang bersangkutan. Dengan adanya pengikatan jaminan kredit berupa harta milik debitur yang bersangkutan takut akan kehilangan hartanya tersebut. Hal ini tentunya memberi motivasi pada debitur untuk menggunakan kredit sebaik-baiknya, serta mengelola kegiatan usaha dan kondisi keuangan secara baik sehingga dengan segera dapat melunasi kreditnya agar dapat menguasai kembali hartanya.

c. Fungsi yang Terkait dengan Pelaksanaan Ketentuan Perbankan Penguasaan dan pengikatan jaminan kredit secara sempurna terkait dengan ketentuan lain di bidang perbankan. Keterkaitan jaminan kredit dengan ketentuan perbankan yang dikeluarkan oleh bank Indonesia, salah satu contohnya mengenai ketentuanketentuan yang mengatur tentang penilaian agunan sebagai faktor pengurang dalam penghitungan PPA.

\section{METODE PENELITIAN}

\subsection{Jenis Penelitian}

Dalam penelitian ini menggunakan metode deskriptif dengan pendekatan kualitatif. Pendekatan deskriptif dilakukan untuk mengidentifikasi dan menjelaskan mengenai objek penelitian. Penelitian kualitatif sering disebut metode penelitian naturalistik karena penelitiannya dilakukan pada kondisi yang alamiah (natural setting), data yang terkumpul dan analisisnya lebih bersifat kualitatif.

\subsection{Variabel Penelitian}

Variabel yang diteliti adalah mengenai penilaian jaminan kredit. Pengumpulan data dan informasi dilakukan menggunakan observasi, wawancara, dan studi pustaka.
Observasi dilakukan dengan cara mengamati secara langsung terhadap objek yang menjadi penelitian penulis. Kemudian wawancara dilakukan secara langsung dengan beberapa marketing perbankan yang menyalurkan kredit UMKM. Studi pustaka dilakukan untuk mendapatkan informasi berupa beberapa pendekatan secara teoritis.

\subsection{Teknik Analisis Data}

Teknik pengolahan data dilakukan dengan mengumpulkan data, dan dianalisis secara deskriptif kualitatif data pendukung lainya.

\section{HASIL DAN PEMBAHASAN \\ 4.1 Jenis Agunan}

Tabel 1. Jenis Agunan

\begin{tabular}{|c|c|}
\hline $\begin{array}{l}\text { Jenis } \\
\text { agunan }\end{array}$ & Persyaratan agunan \\
\hline \multirow[t]{8}{*}{$\begin{array}{c}\text { Tanah } \\
\text { Kosong }\end{array}$} & $\begin{array}{l}\text { 1. Tanah Pekarangan/ Tanah } \\
\text { darat/ Tanah Kebun }\end{array}$ \\
\hline & 2. Tanah Sawah Produktif \\
\hline & $\begin{array}{l}\text { 3. Tanah tambak produktif } \\
\text { dan permanen }\end{array}$ \\
\hline & $\begin{array}{l}\text { 4. Kavling } \\
\text { perumahan }\end{array}$ \\
\hline & Syarat : \\
\hline & $\begin{array}{l}\text { 1. Memiliki } \text { batas-batas } \\
\text { tanah yang jelas }\end{array}$ \\
\hline & $\begin{array}{l}\text { 2. Terdapat akses jalan } \\
\text { masuk ke lokasi agunan } \\
\text { sesuai dengan gambar } \\
\text { situasi/peta lokasi yang } \\
\text { tercantum pada dokumen } \\
\text { agunan, dan dapat dibuktikan } \\
\text { secara fisik. }\end{array}$ \\
\hline & $\begin{array}{l}\text { 3. Akses jalan masuk ke } \\
\text { lokasi agunan minimal } \\
\text { selebar } 1 \text { meter, kecuali } \\
\text { untuk lokasi agunan tanah } \\
\text { sawah dan tanah kebun. }\end{array}$ \\
\hline
\end{tabular}




\begin{tabular}{|l|l|}
\hline & $\begin{array}{l}\text { 4. Apabila terdapat } \\
\text { perbedaan bentuk atau luas } \\
\text { tanah antara gambar situasi } \\
\text { dengan fisik agunan, maka } \\
\text { wajib melampirkan surat } \\
\text { keterangan dari pihak-pihak } \\
\text { yang terkait, yaitu: Kelurahan } \\
\text { atau Kecamatan dan atau } \\
\text { BPN setempat, atau pejabat } \\
\text { lain yang berwenang. }\end{array}$ \\
& $\begin{array}{l}\text { 5. Sawah produktif, adalah } \\
\text { sawah yang memiliki irigasi } \\
\text { permanen dan minimal panen } \\
2 \text { kali dalam setahun. }\end{array}$ \\
\hline
\end{tabular}

\begin{tabular}{|c|c|}
\hline \multirow{8}{*}{$\begin{array}{l}\text { Tanah dan } \\
\text { Bangunan }\end{array}$} & 1. Rumah Tinggal \\
\hline & 2. Ruko \\
\hline & 3. Apartemen \\
\hline & 4. Rumah Susun \\
\hline & Syarat: \\
\hline & $\begin{array}{l}\text { 1. Bangunan layak } \\
\text { huni, bukan bangunan } \\
\text { setengah jadi atau } \\
\text { bangunan masih dalam } \\
\text { tahap pembangunan. }\end{array}$ \\
\hline & $\begin{array}{l}\text { 2. Bukan merupakan } \\
\text { sarana ibadah yang } \\
\text { digunakan } \text { oleh } \\
\text { sekelompok } \\
\text { masyarakat, masyarakat } \\
\text { sekitar atau masyarakat } \\
\text { umum yang dilakukan } \\
\text { secara rutin. }\end{array}$ \\
\hline & $\begin{array}{l}\text { 3. Bukan bangunan } \\
\text { yang digunakan untuk } \\
\text { kepentingan umum, } \\
\text { Sosial atau Politik } \\
\text { (contoh: sekolah, rumah } \\
\text { sakit, puskesmas, } \\
\text { klinik, sekretariat Partai } \\
\text { Politik dan sebagainya). }\end{array}$ \\
\hline $\begin{array}{l}\text { Kios/los/dasaran/ } \\
\text { lapak/ lainnya } \\
\text { yang sejenis }\end{array}$ & $\begin{array}{l}\text { Masa berlakunya dua } \\
\text { tahun sebelum jatuh } \\
\text { tempo kredit. }\end{array}$ \\
\hline Deposito & $\begin{array}{l}\text { Deposito Bank di } \\
\text { tempat calon debitur } \\
\text { mengajukan kredit }\end{array}$ \\
\hline
\end{tabular}

\subsection{Kepemilikan Agunan}

Tabel 2. Kepemilikan Agunan

\begin{tabular}{|c|c|}
\hline $\begin{array}{c}\text { Jenis } \\
\text { agunan }\end{array}$ & Pemilik agunan \\
\hline $\begin{array}{l}\text { A. Tanah } \\
\text { dan } \\
\text { Bangunan }\end{array}$ & 1. Atas nama calon/debitur \\
\hline \multirow[t]{2}{*}{$\begin{array}{l}\text { B. Tanah } \\
\text { Kosong }\end{array}$} & $\begin{array}{l}\text { 2. Atas nama: suami/istri } \\
\text { calon/debitur, orang tua } \\
\text { kandung, anak kandung } \\
\text { calon/debitur. }\end{array}$ \\
\hline & $\begin{array}{l}\text { 3. Diperkenankan atas nama } \\
\text { lebih dari } 1 \text { (satu) orang } \\
\text { sesuai dengan point } 1 \text { dan } 2 \text {. }\end{array}$ \\
\hline A. $\operatorname{Kios}$ & 1. Atas nama calon/debitur \\
\hline B. Lapak & $\begin{array}{l}\text { 2. Atas nama: suami/istri } \\
\text { calon/debitur, orang tua } \\
\text { kandung, anak kandung } \\
\text { calon/debitur. }\end{array}$ \\
\hline C. Dasaran & $\begin{array}{l}\text { 3. Diperkenankan atas } \\
\text { nama lebih dari } 1 \text { (satu) } \\
\text { orang sesuai dengan point } 1 \\
\text { dan 2. }\end{array}$ \\
\hline \multicolumn{2}{|l|}{ D. Los } \\
\hline \multirow[b]{2}{*}{$\begin{array}{l}\text { Kendaraan } \\
\text { Roda } 4 \text { dan } \\
6\end{array}$} & 1. Atas nama calon/debitur \\
\hline & $\begin{array}{l}\text { 2. Atas nama: suami/istri } \\
\text { calon/debitur, orang tua } \\
\text { kandung, anak kandung } \\
\text { calon/debitur. }\end{array}$ \\
\hline \multirow{2}{*}{$\begin{array}{l}\text { Deposito } \\
\text { Bank }\end{array}$} & 1. Atas nama calon/debitur. \\
\hline & $\begin{array}{l}\text { 2. Atas nama: suami/istri } \\
\text { calon/debitur. }\end{array}$ \\
\hline
\end{tabular}

\subsection{LTV (Loan To Value Ratio)}

Yang dimaksudkan dengan LTV Ratio adalah nilai perbandingan antara plafon kredit yang diberikan dengan nilai agunan yang diberikan. Berikut disampaikan besaran LTV yang umunya dipakai perbankan disegement kredit UMKM. 


\begin{tabular}{|l|c|}
\hline \multicolumn{1}{|c|}{ Agunan } & Maximum LTV \\
\hline $\begin{array}{l}\text { Tanah Kosong } \geq \\
1000 \mathrm{~m} 2\end{array}$ & $70 \%$ \\
\hline $\begin{array}{l}\text { Tanah Kosong } \\
<1000 \mathrm{~m} 2\end{array}$ & $80 \%$ \\
\hline $\begin{array}{l}\text { Tanah dan } \\
\text { Bangunan }\end{array}$ & $80 \%$ \\
\hline $\begin{array}{l}\text { Kios / Lapak/ } \\
\text { dasaran / los }\end{array}$ & $\begin{array}{l}\text { Eropa) } \\
\text { Roda 4 dan 6 / } \\
\text { Motor } \\
\text { dan 60\% (buatan } \\
\text { Bilyet Deposito } \\
\text { Rupiah }\end{array}$ \\
\hline \multicolumn{2}{|c|}{$\begin{array}{l}90 \% \\
\end{array}$}
\end{tabular}

\subsection{Jaminan Yang Hindari}

Beberapa kondisi agunan tanah atau tanah dan bangunan yang dihindari:

1. Terkena rencana pelebaran jalan atau penggusuran.

2. Peruntukan untuk jalur hijau.

3. Tanah atau tanah dan bangunan di bawah aliran arus listrik tegangan tinggi (Sutet) minimal radius 30 meter.

4. Mempunyai akses jalan menuju lokasi dan atau lebar jalan kurang dari 1 meter (khusus untuk perumahan).

5. Tanah kuburan/pemakaman/rumah kremasi/atau berada disekitarnya dengan radius minimal 30 meter.

6. Tanah dalam sengketa.

7. Peruntukan sebagian atau seluruhnya sebagai sarana umum dan atau sosial seperti: Sekolah, Rumah Sakit, Puskemas, Klinik, Mesjid, Sekretariat Partai Politik, Lapangan Olah Raga, Gereja dan sejenisnya.

8. Tanah dan Bangunan yang peruntukannya melanggar hukum atau tidak sesuai dengan norma dan ketentuan yang berlaku (perjudian, lingkungan lokalisasi, dll).

9. Kendaraan bermotor yang biasanya dihindari oleh bank adlah kendaraan yang telah dimodifikasi sehingga berubah dari bentuk dan fungsi aslinya,

kendaraan yang diperuntukan untuk hobi.

\section{KESIMPULAN DAN SARAN}

\subsection{Kesimpulan}

1. Jenis jaminan yang umumnya diterima oleh perbankan yang menyalurkan kredit pada segmen kredit UMKM adalah tanah kosong, tanah dan bangunan, kendaraan bermotor roda 4 dan 6, kios, dan deposito.

2. Loan To Value tanah kosong maksimal 70-80\%, tanah dan bangunan, kios maksimal $80 \%$, kendaraan bermotor maksimal $60-70 \%$ dan untuk deposito maksimal $90 \%$.

3. Jaminan yang umumnya di hindari oleh perbankan adalah jaminan yang mempunyai nilai market nya turun disebabkan faktor-faktor kondisi, letak dan fungsi jaminan itu sendiri.

\subsection{Saran}

1. Jaminan merupakan second way out bagi perbankan jika terjadi kredit bermasalah atau kredit macet. Untuk itu perbankan terutama para pengambil keputusan kredit sebaiknya dalam melakukan analisa kelayakan jaminan harus benar-benar menjalankan kebijakan dan Standar operating procedure yang telah ditentukan agar potensi risiko yang mungkin timbul dapat diminimalkan.

2. Bagi para calon debitur agar dapat mengetahui jenis-jenis jaminan yang umumnya diterima perbankan dan jaminan yang dihindari oleh perbankan

\section{DAFTAR PUSTAKA}

Banu Rinaldi. (2020). Jaminan atau Agunan. Retrieved November 26, 2020, from www.ukmindonesia.id website:

https://www.ukmindonesia.id/bacaartikel/249

Kasmir. (2012). Bank dan Lembaga 
Keuangan Lainnya. Jakarta: Raja

Grafindo Persada.

Kasmir. (2012). Dasar-dasar Perbankan.

Jakarta: Rajawali Pers.

M. Bahsan. (2007). Hukum Jaminan dan

Jaminan Kredit Perbankan Indonesia.

Jakarta: RajaGrafindo Persada.

OJK-PEDIA. (2020). Istilah. Retrieved

November 27, 2020, from

https://www.ojk.go.id/id website:

https://www.ojk.go.id/id/ojk-

pedia/default.aspx\#: :text=merupakan

uang tunai dan aset,) tahun (liquid

assets).

Undang-undang RI No. 10. (1998).

Undang-undang RI No. 10 Tahun 1998

Tentang Perubahan Atas Undang-

undang No. 7 Tahun 1992, Tentang

Perbankan. Bank Indonesia.

Wahjono, S. I. (2013). Manajemen

Pemasaran Bank. Yogyakarta: Graha

Ilmu. 